\title{
(๑) Chiari malformation Type I surgery in pediatric patients. Part 2: complications and the influence of comorbid disease in California, Florida, and New York
}

\author{
Jacob K. Greenberg, MD, MSCI, ${ }^{1}$ Margaret A. Olsen, PhD, MPH, ${ }^{2,3}$ \\ Chester K. Yarbrough, MD, MPHS, ${ }^{1}$ Travis R. Ladner, BA, ${ }^{4}$ Chevis N. Shannon, MBA, MPH, DrPH, ${ }^{4}$ \\ Jay F. Piccirillo, MD, ${ }^{5}$ Richard C. E. Anderson, MD, ${ }^{6}$ John C. Wellons III, MD, MSPH, ${ }^{4}$ \\ Matthew D. Smyth, MD, ${ }^{1}$ Tae Sung Park, MD, ${ }^{1}$ and David D. Limbrick Jr., MD, PhD1 \\ Departments of ${ }^{1}$ Neurological Surgery, ${ }^{5}$ Otolaryngology-Head and Neck Surgery, ${ }^{2}$ Medicine, and ${ }^{3}$ Surgery, Washington \\ University School of Medicine in St. Louis, Missouri; ${ }^{4}$ Department of Neurological Surgery, Vanderbilt University Medical Center, \\ Nashville, Tennessee; ${ }^{6}$ Department of Neurosurgery, Columbia University Medical Center, New York, New York
}

\begin{abstract}
OBJECTIVE Chiari malformation Type I (CM-I) is a common and often debilitating pediatric neurological disease. However, efforts to guide preoperative counseling and improve outcomes research are impeded by reliance on small, singlecenter studies. Consequently, the objective of this study was to investigate CM-I surgical outcomes using populationlevel administrative billing data.
\end{abstract}

METHODS The authors used Healthcare Cost and Utilization Project State Inpatient Databases (SID) to study pediatric patients undergoing surgical decompression for CM-I from 2004 to 2010 in California, Florida, and New York. They assessed the prevalence and influence of preoperative complex chronic conditions (CCC) among included patients. Outcomes included medical and surgical complications within 90 days of treatment. Multivariate logistic regression was used to identify risk factors for surgical complications.

RESULTS A total of 936 pediatric CM-I surgeries were identified for the study period. Overall, $29.2 \%$ of patients were diagnosed with syringomyelia and $13.7 \%$ were diagnosed with scoliosis. Aside from syringomyelia and scoliosis, $30.3 \%$ of patients had at least 1 CCC, most commonly neuromuscular (15.2\%) or congenital or genetic (8.4\%) disease. Medical complications were uncommon, occurring in $2.6 \%$ of patients. By comparison, surgical complications were diagnosed in $12.7 \%$ of patients and typically included shunt-related complications (4.0\%), meningitis (3.7\%), and other neurosurgeryspecific complications (7.4\%). Major complications (e.g., stroke or myocardial infarction) occurred in $1.4 \%$ of patients. Among children with CCCs, only comorbid hydrocephalus was associated with a significantly increased risk of surgical complications (OR 4.5, 95\% Cl 2.5-8.1).

CONCLUSIONS Approximately 1 in 8 pediatric CM-I patients experienced a surgical complication, whereas medical complications were rare. Although CCCs were common in pediatric CM-I patients, only hydrocephalus was independently associated with increased risk of surgical events. These results may inform patient counseling and guide future research efforts.

http://thejns.org/doi/abs/10.3171/2015.10.PEDS15369

KEY WORDS Chiari malformation Type I; neurosurgery; health services research; postoperative complications

I DENTIFIED in up to $4 \%$ of brain and cervical spine MRI studies, Chiari malformation Type I (CM-I) is a common diagnosis in children. ${ }^{21,27}$ While the surgical treatment of CM-I is one of the most common pediatric neurosurgical procedures, ${ }^{5}$ the evidence guiding CM-I management is derived primarily from single-center series from academic institutions. Therefore, although CM-I surgery is typically an elective intervention rooted in the assumption that benefits outweigh the risks of postoperative complications, there are currently insufficient data

ABBREVIATIONS CCC = complex chronic condition; CM-I = Chiari malformation Type I; CM-II = Chiari malformation Type II; HCUP = Healthcare Cost and Utilization Project; ICD-9-CM = International Classification of Diseases, Ninth Revision, Clinical Modification; SID = State Inpatient Databases.

SUBMITTED June 15, 2015. ACCEPTED October 14, 2015.

INCLUDE WHEN CITING Published online January 22, 2016; DOI: 10.3171/2015.10.PEDS15369. 
to guide patients and families considering surgery. To improve patient selection and preoperative counseling, large-scale, multicenter data are needed to assess the risks of operative morbidity.

One efficient method of studying treatment outcomes at a population level is through the use of administrative billing databases, which are produced by a variety of public and private organizations. ${ }^{12}$ Particularly useful for assessments of surgical morbidity, mortality, and resource utilization, administrative databases have been used to study the operative risk associated with a variety of neurosurgical interventions. ${ }^{4,20,29,30}$ Recent analyses using administrative claims data have shown that inpatient complications following adult CM-I surgery were remarkably common-occurring in almost one-fifth of casesand were particularly prevalent in cases involving patients with certain preoperative comorbidities. ${ }^{9}$ To our knowledge, only one study has used billing data to investigate CM-I surgical outcomes in children. However, that study identified patients using billing codes of uncertain validity, focused exclusively on index admission complications rather than complications observed after discharge from the initial hospitalization, and assessed comorbidities primarily relevant to adult populations. ${ }^{23}$

Addressing these shortcomings, the objective of this study was to use administrative billing data to evaluate the morbidity associated with pediatric CM-I surgery, with a particular focus on the influence of chronic preoperative comorbidities relevant to children.

\section{Methods \\ Data Source}

We used State Inpatient Databases (SID) produced by the Healthcare Cost and Utilization Project (HCUP) of the Agency for Healthcare Research and Quality (http://www. hcup-us.ahrq.gov/sidoverview.jsp). The SID are comprehensive administrative databases containing billing information on diagnoses and procedures from all nonfederal hospital admissions in participating states. In addition, some SID include an encrypted patient identifier to link hospitalizations over time. We used data from the California, Florida, and New York SID, which all include the identifier linking hospitalizations, permitting longitudinal assessment of complications.

\section{Inclusion/Exclusion Criteria}

We used a recently validated International Classification of Diseases, Ninth Revision, Clinical Modification (ICD-9-CM) code algorithm (primary discharge diagnosis of 348.4 plus a procedure code of 01.24 or 03.09$)^{15}$ to identify CM-I surgeries. We included patients 18 years or younger who received a CM-I decompression surgery in California (2004-2010), Florida (2006-2010), or New York (2006-2010). We chose this study period to allow 1 year prior to admission to assess preoperative comorbidities and 1 year after surgery to assess outcome. To ensure that index surgeries did not represent a complication from recent treatment, we excluded patients who underwent CM-I surgery in the year 2003 (California) or 2005 (Florida and New York). We also excluded patients whose home state was different from the state where they received surgery, since such patients may be readmitted to an out-of-state hospital not included in the SID, as well as patients with a diagnosis code of 741.0 (Chiari malformation Type II [CM-II]).

\section{Comorbidities}

To evaluate the impact of preoperative comorbidities on postoperative outcome, we focused on the influence of complex chronic conditions (CCCs) in children. ${ }^{8} \mathrm{Com}-$ pared with the Elixhauser groupings ${ }^{6}$ often used to study adult patients, ${ }^{19,20} \mathrm{CCC}$ include diagnoses relevant to pediatric patients and have been used previously to study pediatric neurosurgical outcomes. ${ }^{25,26}$ In particular, this system uses ICD-9-CM diagnosis codes to define cardiovascular, congenital or genetic, gastrointestinal, hematological and immunodeficiency-related, metabolic, neoplastic, neuromuscular, respiratory, and renal disease. We modified the category for neuromuscular disease to remove the coding for spina bifida (741.0X) and to independently evaluate hydrocephalus $(331.3,331.4,331.5,742.3)$ and syringomyelia (336.0), which are of particular interest in CM-I patients. Likewise, we evaluated scoliosis (737.3X) separately from the other diagnoses in the congenital or genetic disease category. Finally, we supplemented the ICD-9-CM codes used to define the neoplastic category in the $\mathrm{CCC}$ grouping with additional diagnosis codes from the Elixhauser comorbidity index (258.01-258.03, 789.51).

\section{Outcome}

We assessed postoperative complications within 90 days of index surgery. Using previously published classifications, we divided complications into surgical complications directly related to operative intervention and medical complications related to prolonged illness and hospitalization.9 Surgical complications included wound infection or disruption; bleeding complication; dural graft complication; meningitis, CSF-related complication (e.g., pseudomeningocele and shunt insertion or revision); cerebrovascular infarct or hemorrhage; and other nervous system complications not specified further. As previously reported, we included within the surgical complications category a grouping of "neurosurgery-specific complications." 9 This subcategory included diagnoses such as dural puncture (349.31) and meninges disorders-including pseudomeningocele (349.2) - along with diagnoses such as central nervous system complication (997.01) and other nervous system complication (997.09) that are not precisely defined but can be used for complications such as CSF leak or pseudomeningocele. Medical complications included: cardiac, respiratory, thromboembolic, or urinaryrenal complications; pneumonia; Grade III or IV pressure ulcer; septicemia or catheter-related infection (including catheter-associated urinary tract infection); and tracheostomy or gastrostomy placement. Finally, we separately defined a category of major complications with particularly severe consequences. This group included myocardial infarction or cardiac failure; pulmonary embolism; or iatrogenic cerebrovascular infarction or hemorrhage. 


\section{Statistical Analysis}

We used standard descriptive statistics to describe population demographic characteristics. The bivariate relationship between preoperative characteristics and postoperative outcome was evaluated using logistic regression analysis. To identify independent predictors of operative morbidity, we performed multivariate logistic regression. For logistic regression analyses, generalized estimating equations were used to account for patient clustering within hospitals. Variables with $\mathrm{p}<0.2$ and approximately 10 outcome events were entered, and those with $\mathrm{p}<0.1$ were retained in the final model. Multivariate models were based on complete case analysis of subjects without missing data, and those variables with more missing data were removed first during the model selection process.

All analyses were performed using SAS version 9.2 (SAS Institute), and cumulative incidence curves were created using a publically available SAS macro (KMPLOT9; http://www.hsph.harvard.edu/donna-spiegelman/soft ware/kmplot9/). The study was exempt from review by the Washington University in St. Louis institutional review board.

\section{Results}

We identified 936 patients who received CM-I surgery in the states included in this study during the study period. The vast majority (96\%) of surgeries were done at teaching hospitals. The patients' median age was 10 years (interquartile range 6-15 years) and $50.4 \%$ were female. Most patients (62.1\%) were white and had private insurance $(60.0 \%)$. Overall, $29.2 \%$ of patients were diagnosed with syringomyelia and $13.7 \%$ were diagnosed with scoliosis. Almost one-third of patients $(30.3 \%)$ had at least 1 $\mathrm{CCC}$ other than syringomyelia or scoliosis. The most common specific CCCs were neuromuscular diseases (15.2\%) and congenital or genetic diseases (8.4\%). A complete list of population demographic characteristics and comorbid diagnoses is shown in Table 1.

Surgical complications were diagnosed in $4.5 \%$ of patients during the index admission, whereas medical complications were diagnosed in $2.2 \%$. Considering the full 90-day follow-up period, $12.7 \%$ of patients experienced a surgical complication and $2.6 \%$ experienced a medical complication. As shown in Fig. 1, surgical diagnoses gradually accumulated until reaching a plateau around 60 days postoperatively. By comparison, almost all medical diagnoses occurred during or soon after the index admission. Less than $1 \%$ of patients died during the study period, whereas $1.4 \%$ experienced a major complication (myocardial infarction, iatrogenic stroke, or pulmonary embolism).

The most common individual surgical complications were shunt-related complications (4.0\%), meningitis (3.7\%), and other neurosurgery-specific complications that lacked unique diagnosis codes (e.g., CSF leak) (7.4\%) (Table 2). Aseptic meningitis was the most common type of meningitis diagnosed ( $\mathrm{n}=18 ; 1.9 \%$ of patients). No medical complications reached the HCUP-defined threshold of greater than 10 events needed to report individual outcomes.

The association between various demographic charac-
TABLE 1. Demographic characteristics, comorbidities, and postoperative complications among pediatric patients undergoing $\mathrm{CM}$-I decompression surgery

\begin{tabular}{|c|c|c|}
\hline Variable & No. of Pts & $\%$ \\
\hline Total & 936 & 100 \\
\hline \multicolumn{3}{|l|}{ Age (yrs) } \\
\hline $0-5$ & 228 & 24.4 \\
\hline $6-12$ & 332 & 35.5 \\
\hline $13-18$ & 376 & 40.2 \\
\hline \multicolumn{3}{|l|}{ Sex $^{*}$} \\
\hline Male & 448 & 49.6 \\
\hline Female & 456 & 50.4 \\
\hline \multicolumn{3}{|l|}{ Race $^{*}$} \\
\hline White & 537 & 62.1 \\
\hline Black & 73 & 8.4 \\
\hline Hispanic & 181 & 20.9 \\
\hline Other & 74 & 8.6 \\
\hline \multicolumn{3}{|l|}{ Payer status } \\
\hline Private & 562 & 60.0 \\
\hline Medicaid & 299 & 31.9 \\
\hline Other & 75 & 8.0 \\
\hline \multicolumn{3}{|l|}{ Comorbidity } \\
\hline Cardiovascular disease & 46 & 4.9 \\
\hline Congenital or genetic disease & 79 & 8.4 \\
\hline Gastrointestinal disease & $-\dagger$ & $-\dagger$ \\
\hline Hematol or immunol disease & 14 & 1.5 \\
\hline Hydrocephalus & 61 & 6.5 \\
\hline Metabolic disease & 11 & 1.2 \\
\hline Neoplastic disease & $-\dagger$ & $-\dagger$ \\
\hline Neuromuscular disease & 142 & 15.2 \\
\hline Renal disease & $-\dagger$ & $-\dagger$ \\
\hline Respiratory disease & 12 & 1.3 \\
\hline Scoliosis & 128 & 13.7 \\
\hline Syringomyelia & 273 & 29.2 \\
\hline \multicolumn{3}{|l|}{ Complications } \\
\hline Surgical & 119 & 12.7 \\
\hline Medical & 24 & 2.6 \\
\hline Major $\ddagger$ & 13 & 1.4 \\
\hline
\end{tabular}

Hematol $=$ hematological; immunol $=$ immunological .

* Sum of all groups is less than 936 due to the presence of missing data for sex $(n=32)$ and race $(n=71)$.

$\dagger$ Suppressed because of cell size of 10 or less, due to restrictions defined by the Healthcare Cost and Utilization Project.

‡ Includes myocardial infarction/heart failure, pulmonary embolism, and iatrogenic cerebrovascular infarction or hemorrhage.

teristics and CCCs and the development of postoperative surgical complications is shown in Table 3. In bivariate analysis, several comorbidities-including hydrocephalus (OR 4.6), neuromuscular disease (OR 1.8), and congenital or genetic disease (OR 2.0) -were associated with increased risk of complications. Complications were also more frequent in patients $0-5$ years (OR 2.5) and 13-18 
Surgical Complications

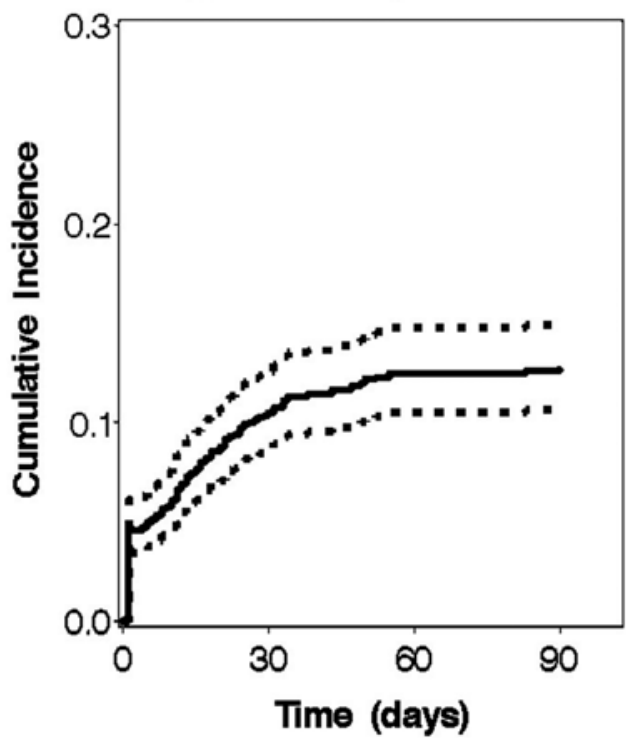

Medical Complications

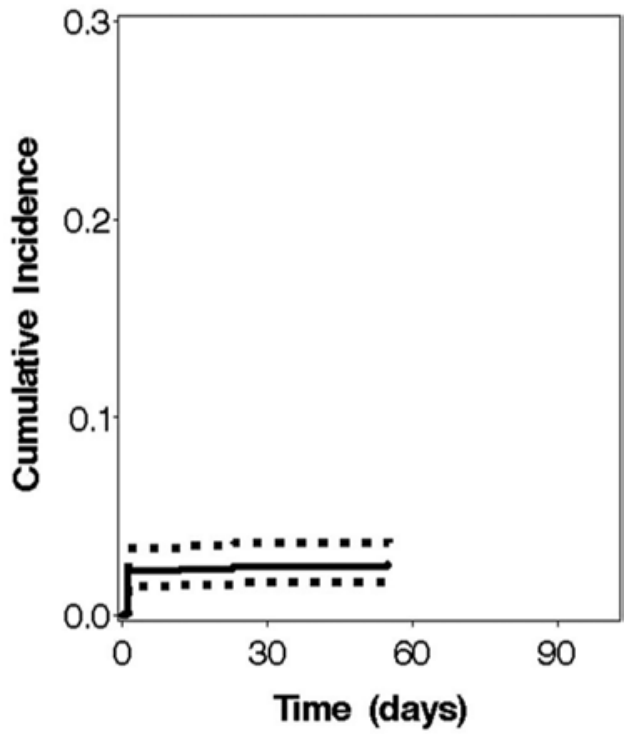

FIG. 1. Cumulative incidence curves with $95 \%$ confidence intervals showing the time-course of postoperative surgical and medical complications during the 90 -day follow-up period. The cumulative incidence curve for medical complications ended before 90 days to indicate the time of the last recorded complication during the study period.

years (OR 2.3) of age compared with those 6-12 years of age. In multivariate analysis, hydrocephalus was the only comorbidity significantly associated with surgical complications (OR 4.5), while neuromuscular diseases had a marginal association (OR 1.7, 95\% CI 0.95-3.2). Age also remained a significant predictor, with patients aged $0-5$ years (OR 2.4) or 13-18 years (OR 2.5) having greater risk of surgical complications than those 6-12 years.

Risk factors for medical complications are shown in Table 4. In bivariate analysis, comorbidities significantly associated with increased risk of medical complications

TABLE 2. The most common individual surgical complications diagnosed within 90 days of $\mathrm{CM}-\mathrm{I}$ surgery*

\begin{tabular}{lc}
\hline \multicolumn{1}{c}{ Complication } & No. $(\%)^{*}$ \\
\hline Shunt insertion, revision, or exploration & $37(4.0)$ \\
\hline Meningitis & $35(3.7) \dagger$ \\
\hline \multicolumn{1}{c}{ Bacterial } & $-\ddagger$ \\
\hline Aseptic & $18(1.9)$ \\
\hline$\quad$ Unspecified§ & $11(1.2)$ \\
\hline Dural graft (device) complication & $19(2.0)$ \\
\hline Wound infection & $15(1.6)$ \\
\hline $\begin{array}{l}\text { Other neurosurgery-specific complications not specified } \\
\quad \text { individually (e.g., CSF leak, pseudomeningocele) }\end{array}$ & $69(7.4)$ \\
\hline Total & $119(12.7)$ \\
\hline
\end{tabular}

* The percentage values refer to the proportion of the total population diagnosed with the respective complication.

$\dagger$ Sum of all meningitis groups is greater than 35 due to the presence of children diagnosed with more than 1 type of meningitis.

¥ Suppressed because of cell size of 10 or less, due to restrictions defined by the Healthcare Cost and Utilization Project.

$\S$ Refers to meningitis of unspecified cause, denoted by ICD-9-CM diagnosis code 322.9 . included cardiovascular disease (OR 11.8), hydrocephalus (OR 4.0), and neuromuscular disease (OR 2.9). Medicaid insurance (OR 2.8 vs private insurance) and black (OR 3.9 vs white) or Hispanic (OR 3.5) race were also significant risk factors for medical complications, while older age (13-18 years) was associated with marginally increased risk (OR 4.6, 95\% CI 0.89-23.4, vs patients $0-5$ years). Due to the relatively small number of medical complications, multivariate analysis to identify independent predictors was not possible.

\section{Discussion}

In this analysis of SID billing data from 3 large states, we performed a population-level analysis of operative morbidity from pediatric CM-I surgery, with a focus on the influence of CCCs. In a cohort of almost 1000 pediatric CM-I patients, we found that approximately 1 in every 8 patients experienced an inpatient surgical complication within 90 days of treatment, whereas less than $3 \%$ experienced a medical complication. In addition, we found that CCCs were common in pediatric CM-I patients-30\% had at least 1 comorbidity-although most were not independently associated with increased the risk of complications.

To date, studies have reported a wide range of complication rates associated with pediatric CM-I surgery. $5,11,14,18,28$ For example, 1 meta-analysis found that complication rates among pediatric patients undergoing posterior fossa decompression with duraplasty ranged from $8 \%$ to $67 \%$, although the sample size for each included study ranged from only 9 to 90 patients. ${ }^{5}$ By comparison, 1 retrospective study of 500 surgeries-mostly with duraplastyfound that complications occurred in less than $3 \%$ of cases, ${ }^{28}$ and a review article cited complication rates as low as $0 \%{ }^{11}$ Such disparate outcomes reflect a reliance on 
TABLE 3. Bivariate and multivariate analysis of factors influencing the risk of postoperative surgical complications

\begin{tabular}{|c|c|c|c|c|}
\hline \multirow[b]{2}{*}{ Factor } & \multicolumn{2}{|c|}{ Bivariate } & \multicolumn{2}{|c|}{ Multivariate } \\
\hline & OR $(95 \% \mathrm{Cl})$ & $p$ Value & OR $(95 \% \mathrm{Cl})$ & $p$ Value \\
\hline Comorbidity & & & NA & - \\
\hline Cardiovascular disease & $1.6(0.8-3.4)$ & 0.17 & NA & - \\
\hline Gastrointestinal disease & NA & - & NA & - \\
\hline Congenital or genetic disease & $2.0(1.2-3.4)$ & 0.01 & NA & - \\
\hline Hematol or immunol disease & $1.2(0.35-3.9)$ & 0.80 & NA & - \\
\hline Hydrocephalus & $4.6(2.6-8.1)$ & $<0.001$ & $4.5(2.5-8.1)$ & $<0.001$ \\
\hline Metabolic disease & $2.3(0.72-7.6)$ & 0.15 & NA & - \\
\hline Neoplastic disease & NA & - & NA & - \\
\hline Neuromuscular disease & $1.8(1.02-3.1)$ & 0.04 & $1.7(0.95-3.2)$ & 0.07 \\
\hline Renal disease & NA & - & NA & - \\
\hline Respiratory disease & $3.0(0.72-12.8)$ & 0.13 & NA & - \\
\hline Scoliosis & $0.98(0.57-1.7)$ & 0.95 & NA & - \\
\hline Syringomyelia & $1.1(0.73-1.6)$ & 0.66 & NA & - \\
\hline \multicolumn{5}{|l|}{ Payer status } \\
\hline Private & Reference & - & NA & - \\
\hline Medicaid & $0.96(0.59-1.6)$ & 0.88 & NA & - \\
\hline Other & $1.9(0.96-3.8)$ & 0.07 & NA & - \\
\hline \multicolumn{5}{|l|}{ Age (yrs) } \\
\hline $0-5$ & $2.5(1.4-4.5)$ & & $2.4(1.3-4.3)$ & 0.006 \\
\hline $6-12$ & Reference & 0.003 & Reference & - \\
\hline $13-18$ & $2.3(1.4-3.7)$ & 0.66 & $2.5(1.5-4.1)$ & $<0.001$ \\
\hline \multicolumn{5}{|l|}{ Sex } \\
\hline Male & Reference & - & NA & - \\
\hline Female & $0.86(0.60-1.2)$ & 0.43 & NA & - \\
\hline \multicolumn{5}{|l|}{ Race } \\
\hline White & Reference & - & NA & - \\
\hline Black & $1.1(0.51-2.5)$ & 0.77 & NA & - \\
\hline Hispanic & $1.4(0.88-2.4)$ & 0.14 & NA & - \\
\hline Other & $1.4(0.80-2.6)$ & 0.23 & NA & - \\
\hline
\end{tabular}

NA = not applicable.

small single-center studies that often employ inconsistent follow-up procedures and outcome measures. These shortcomings emphasize the need for large, multicenter evaluations of postoperative morbidity.

To our knowledge, only 1 study has evaluated pediatric CM-I surgical outcomes using administrative data. However, the ICD-9-CM codes used to define that cohort have not been validated, and in fact included diagnoses such as CM-II and spina bifida. ${ }^{23}$ In addition, that study using the Kids' Inpatient Database only examined outcomes during the index admission, whereas we found that most complications from CM-I surgery occur on a delayed basis well after discharge from initial hospitalization (Fig. 1). ${ }^{9}$ By comparison, the analysis presented herein used a validated ICD-9-CM code algorithm for identifying CM-I surgeries and evaluated complications for 90 days after surgery.

Using such rigorous methods, we found that major complications, such as myocardial infarction and stroke, were rare but still occurred in more than $1 \%$ of surgeries, indicating such risks cannot be dismissed. Surgical complications were more common, experienced by approximately $13 \%$ of patients during the follow-up period. This estimate excludes minor complications managed on an outpatient basis, such as aseptic meningitis or minor wound infection, which would likely have been included in previous case series publications. Consequently, while many of the observed complications may not have led to lasting harm, they may shape decision making for physicians and families considering CM-I surgery.

Beyond assessing overall complication rates, we also investigated risk factors for surgical complications, including demographic characteristics and comorbid diseases. While payer status and race were not associated with surgical complications, children 6-12 years were at lower risk for surgical complications than younger or older groups. While this finding should be replicated in other large populations, we suspect that this result may relate to unmeasured variation in surgical techniques and indications for surgery between younger and older children.,10

Consistent with data showing that CCCs account for 
TABLE 4. Bivariate analysis of factors influencing the risk of postoperative medical complications

\begin{tabular}{|c|c|c|}
\hline Factor & OR $(95 \% \mathrm{Cl})$ & $\mathrm{p}$ Value \\
\hline \multicolumn{3}{|l|}{ Comorbidity } \\
\hline Cardiovascular disease & $11.8(4.5-31.1)$ & $<0.001$ \\
\hline Gastrointestinal disease & NA & - \\
\hline Congenital or genetic disease & $0.47(0.07-3.2)$ & 0.44 \\
\hline Hematol or immunol disease & NA & - \\
\hline Hydrocephalus & $4.0(1.4-11.8)$ & 0.01 \\
\hline Metabolic disease & $3.9(0.46-33.3)$ & 0.21 \\
\hline Neoplastic disease & NA & - \\
\hline Neuromuscular disease & $2.9(1.1-7.6)$ & 0.02 \\
\hline Renal disease & NA & - \\
\hline Respiratory disease & $3.6(0.47-27.0)$ & 0.22 \\
\hline Scoliosis & $0.57(0.14-2.2)$ & 0.42 \\
\hline Syringomyelia & $1.5(0.70-3.1)$ & 0.30 \\
\hline \multicolumn{3}{|l|}{ Payer status } \\
\hline Private & Reference & - \\
\hline Medicaid & $2.8(1.1-7.2)$ & 0.03 \\
\hline Other & $1.7(0.42-6.9)$ & 0.45 \\
\hline \multicolumn{3}{|l|}{ Age (yrs) } \\
\hline $0-5$ & Reference & \\
\hline $6-12$ & $2.9(0.57-14.6)$ & 0.20 \\
\hline $13-18$ & $4.6(0.89-23.4)$ & 0.07 \\
\hline \multicolumn{3}{|l|}{ Sex } \\
\hline Male & Reference & - \\
\hline Female & $0.59(0.27-1.3)$ & 0.18 \\
\hline \multicolumn{3}{|l|}{ Race } \\
\hline White & Reference & - \\
\hline Black & $3.9(1.3-11.4)$ & 0.01 \\
\hline Hispanic & $3.5(1.4-8.6)$ & 0.006 \\
\hline Other & $1.8(0.38-8.1)$ & 0.47 \\
\hline
\end{tabular}

a substantial and increasing proportion of inpatient hospitalizations $^{24}$ and hospital costs ${ }^{3,24}$ in the United States, we also found that almost one-third of our population was diagnosed with a CCC. However, only patients with comorbid hydrocephalus were at significantly increased risk of surgical complications, while neuromuscular disease was associated with marginally increased risk. Although this finding may partially reflect undercoding, the rarity of certain CCCs, or unmeasured confounders, these results suggest that most children with CCCs can undergo CM-I surgery without increased concern for complications such as CSF leak, pseudomeningocele, and meningitis.

Due to the scarcity of medical complications, a multivariate analysis was not possible, and the precision of our bivariate analyses was relatively low. Nonetheless, our results suggest that certain CCCs-including hydrocephalus, cardiovascular disease, and neuromuscular disease - may be associated with increased risk of medical complications, a finding consistent with data showing that CCCs are associated with venous thromboembolism ${ }^{22}$ and Clostridium difficile infection. ${ }^{13}$ In addition, while most patients were white and privately insured, medical complications were more common in black and Hispanic patients and those with Medicaid insurance. While we could not disentangle the known confounding between race and socioeconomic status ${ }_{16}^{16}$ our analysis suggests that although medical complications after CM-I surgery are rare, certain underserved groups may be at increased risk.

While this study provides novel insight into the characteristics and surgical outcomes of pediatric CM-I patients, it has several limitations. First, the preoperative comorbidities and postoperative outcomes analyzed were defined using ICD-9-CM diagnosis codes that were not recorded for research purposes and may be inaccurate or incomplete in some instances. In particular, our finding that $1.4 \%$ of children undergoing CM-I surgery experience a major complication-events typically seen in adult populations-could potentially be explained, in part, by coding inaccuracies. However, the CCCs used have been widely published, ${ }^{2,7,8,24}$ and previous studies have shown that ICD-9-CM coding for surgical complications is generally reliable and is typically more accurate than coding for complications from medical treatment. ${ }^{17}$ Second, the diagnosis of comorbid hydrocephalus, a comorbidity of particular prognostic importance in this study, was made exclusively using ICD-9CM diagnosis codes $(331.3,331.4,331.5,742.3)$, which did not distinguish shunt-treated children from those who were untreated or treated by endoscopic third ventriculostomy. Future studies using more detailed data sets may investigate potential differences among these subgroups. Third, due to a lack of information in the billing data, we were unable to evaluate surgical technique, surgeon experience, or surgical indication, potentially important determinants of clinical outcome. Finally, certain CCCs, such as respiratory or metabolic disease, were rare in our cohort, and consequently we may have been underpowered to evaluate their influence on postoperative outcome.

\section{Conclusions}

This study provides population-level evidence that among pediatric patients undergoing CM-I decompression surgery, medical complications are uncommon and major morbidity and mortality are exceedingly rare. However, approximately 1 in 8 patients experience a surgical complication, and those children with comorbid hydrocephalus may be at greater risk. These results should inform treatment decisions and guide future studies using more detailed data sets.

\section{Acknowledgments}

We thank Mr. Nicholas White for assistance with database programming. We thank Dr. Yan Yan for his input regarding the statistical analyses conducted in this study. This work was supported by the Clinical and Translational Science Award (CTSA) program of the National Center for Advancing Translational Sciences (NCATS) of the National Institutes of Health (NIH) under Award Numbers UL1 TR000448 and TL1 TR000449 and by funding from the Agency for Healthcare Research and Quality (R24 HS19455). This work was also supported in part through grants from the American Syringomyelia \& Chiari Alliance Project (ASAP) and Washington University School of Medicine as well as philanthropic funding provided by the Park-Reeves Syringomyelia 
Research Consortium, the O'Keefe family, and Mateo Dalla Fontana. T.R.L. was also supported by a Council of State Neurosurgical Societies/Congress of Neurological Surgeons Medical Student Fellowship. None of the funding agencies had a direct role in the study design and conduct; data collection, management, analysis, or interpretation; preparing, reviewing, or approving the manuscript prior to submission; or the decision to submit the manuscript for publication.

\section{References}

1. Albert GW, Menezes AH, Hansen DR, Greenlee JDW, Weinstein SL: Chiari malformation Type I in children younger than age 6 years: presentation and surgical outcome. J Neurosurg Pediatr 5:554-561, 2010

2. Berry JG, Hall DE, Kuo DZ, Cohen E, Agrawal R, Feudtner $\mathrm{C}$, et al: Hospital utilization and characteristics of patients experiencing recurrent readmissions within children's hospitals. JAMA 305:682-690, 2011

3. Cohen E, Berry JG, Camacho X, Anderson G, Wodchis W, Guttmann A: Patterns and costs of health care use of children with medical complexity. Pediatrics 130:e1463-e1470, 2012

4. Deyo RA, Mirza SK, Martin BI, Kreuter W, Goodman DC, Jarvik JG: Trends, major medical complications, and charges associated with surgery for lumbar spinal stenosis in older adults. JAMA 303:1259-1265, 2010

5. Durham SR, Fjeld-Olenec K: Comparison of posterior fossa decompression with and without duraplasty for the surgical treatment of Chiari malformation Type I in pediatric patients: a meta-analysis. J Neurosurg Pediatr 2:42-49, 2008

6. Elixhauser A, Steiner C, Harris DR, Coffey RM: Comorbidity measures for use with administrative data. Med Care 36:8-27, 1998

7. Feudtner C, Feinstein JA, Satchell M, Zhao H, Kang TI: Shifting place of death among children with complex chronic conditions in the United States, 1989-2003. JAMA 297:2725-2732, 2007

8. Feudtner C, Hays RM, Haynes G, Geyer JR, Neff JM, Koepsell TD: Deaths attributed to pediatric complex chronic conditions: national trends and implications for supportive care services. Pediatrics 107:E99, 2001

9. Greenberg JK, Ladner TR, Olsen MA, Shannon CN, Liu J, Yarbrough CK, et al: Complications and resource use associated with surgery for Chiari malformation Type 1 in adults: a population perspective. Neurosurgery 77:261-268, 2015

10. Greenlee JD, Donovan KA, Hasan DM, Menezes AH: Chiari I malformation in the very young child: the spectrum of presentations and experience in 31 children under age 6 years. Pediatrics 110:1212-1219, 2002

11. Hankinson T, Tubbs RS, Wellons JC: Duraplasty or not? An evidence-based review of the pediatric Chiari I malformation. Childs Nerv Syst 27:35-40, 2011

12. Iezzoni LI: Assessing quality using administrative data. Ann Intern Med 127:666-674, 1997

13. Kim J, Smathers SA, Prasad P, Leckerman KH, Coffin S, Zaoutis T: Epidemiological features of Clostridium difficileassociated disease among inpatients at children's hospitals in the United States, 2001-2006. Pediatrics 122:1266-1270, 2008

14. Ladner TR, Dewan MC, Day MA, Shannon CN, Tomycz L, Tulipan N, et al: Evaluating the relationship of the pB-C2 line to clinical outcomes in a 15 -year single-center cohort of pediatric Chiari I malformation. J Neurosurg Pediatr 15:178-188, 2015

15. Ladner TR, Greenberg JK, Guerrero N, Olsen MA, Shannon CN, Yarbrough CK, et al: Chiari malformation Type I surgery in pediatric patients. Part 1: validation of an ICD9-CM code search algorithm. J Neurosurg Pediatr [epub ahead of print January 22, 2016. DOI: 10.3171/2015.10. PEDS15370]

16. LaVeist TA: Disentangling race and socioeconomic status: a key to understanding health inequalities. J Urban Health 82 (2 Suppl 3):iii26-iii34, 2005

17. Lawthers AG, McCarthy EP, Davis RB, Peterson LE, Palmer RH, Iezzoni LI: Identification of in-hospital complications from claims data. Is it valid? Med Care 38:785-795, 2000

18. Lee A, Yarbrough CK, Greenberg JK, Barber J, Limbrick DD, Smyth MD: Comparison of posterior fossa decompression with or without duraplasty in children with Type I Chiari malformation. Childs Nerv Syst 30:14191424,2014

19. Li G, Patil CG, Lad SP, Ho C, Tian W, Boakye M: Effects of age and comorbidities on complication rates and adverse outcomes after lumbar laminectomy in elderly patients. Spine (Phila Pa 1976) 33:1250-1255, 2008

20. McClelland S III, Guo H, Okuyemi KS: Population-based analysis of morbidity and mortality following surgery for intractable temporal lobe epilepsy in the United States. Arch Neurol 68:725-729, 2011

21. Meadows J, Kraut M, Guarnieri M, Haroun RI, Carson BS: Asymptomatic Chiari Type I malformations identified on magnetic resonance imaging. J Neurosurg 92:920-926, 2000

22. Raffini L, Huang YS, Witmer C, Feudtner C: Dramatic increase in venous thromboembolism in children's hospitals in the United States from 2001 to 2007. Pediatrics 124:1001-1008, 2009

23. Shweikeh F, Sunjaya D, Nuno M, Drazin D, Adamo MA: National trends, complications, and hospital charges in pediatric patients with Chiari malformation type I treated with posterior fossa decompression with and without duraplasty. Pediatr Neurosurg 50:31-37, 2015

24. Simon TD, Berry J, Feudtner C, Stone BL, Sheng X, Bratton SL, et al: Children with complex chronic conditions in inpatient hospital settings in the United States. Pediatrics 126:647-655, 2010

25. Simon TD, Hall M, Riva-Cambrin J, Albert JE, Jeffries HE, Lafleur B, et al: Infection rates following initial cerebrospinal fluid shunt placement across pediatric hospitals in the United States. Clinical article. J Neurosurg Pediatr 4:156-165, 2009

26. Simon TD, Riva-Cambrin J, Srivastava R, Bratton SL, Dean JM, Kestle JR: Hospital care for children with hydrocephalus in the United States: utilization, charges, comorbidities, and deaths. J Neurosurg Pediatr 1:131-137, 2008

27. Strahle J, Muraszko KM, Kapurch J, Bapuraj JR, Garton HJ, Maher CO: Chiari malformation Type I and syrinx in children undergoing magnetic resonance imaging. $\mathbf{J}$ Neurosurg Pediatr 8:205-213, 2011

28. Tubbs RS, Beckman J, Naftel RP, Chern JJ, Wellons JC III, Rozzelle CJ, et al: Institutional experience with 500 cases of surgically treated pediatric Chiari malformation Type I. J Neurosurg Pediatr 7:248-256, 2011

29. Wen T, Attenello FJ, He S, Cen Y, Kim-Tenser MA, Sanossian N, et al: Racial and socioeconomic disparities in incidence of hospital-acquired complications following cerebrovascular procedures. Neurosurgery 75:43-50, 2014

30. Zacharia BE, Deibert C, Gupta G, Hershman D, Neugut AI, Bruce JN, et al: Incidence, cost, and mortality associated with hospital-acquired conditions after resection of cranial neoplasms. Neurosurgery 74:638-647, 2014

\section{Disclosures}

The authors report no conflict of interest concerning the materials or methods used in this study or the findings specified in this paper. 


\section{Supplemental Information}

\section{Companion Papers}

Ladner TR, Greenberg JK, Guerrero N, Olsen MA, Shannon $\mathrm{CN}$, Yarbrough CK, et al: Chiari malformation Type I surgery in pediatric patients. Part 1: validation of an ICD-9-CM code search algorithm. DOI: 10.3171/2015.10.PEDS15370.

\section{Previous Presentations}

A presentation based on these results was delivered at the 43rd Annual Meeting of the AANS/CNS Joint Section on Pediatric Neurosurgery, Amelia Island, Florida, December 2-5, 2014.

\section{Author Contributions}

Conception and design: Greenberg, Yarbrough, Limbrick. Analysis and interpretation of data: all authors. Drafting the article: Greenberg. Critically revising the article: all authors. Reviewed submitted version of manuscript: all authors. Approved the final version of the manuscript on behalf of all authors: Greenberg. Study supervision: Limbrick.

\section{Correspondence}

Jacob K. Greenberg, St. Louis Children's Hospital, One Children's Way, 4S20, St. Louis, MO 63110. email: greenbergj@ wudosis.wustl.edu. 